\title{
STABILITY OF SKELETAL CLASS III MALOCCLUSION AFTER ORTHOGNATHIC SURGERY AND ORTHODONTIC TREATMENT: A SYSTEMATIC REVIEW AND META-ANALYSIS
}

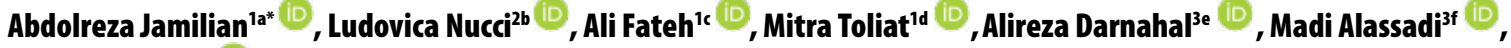 \\ Chin Wei Wang ${ }^{3 g}$ (D)
}

'Department of Orthodontics, Cranio-Maxillofacial Research Center, Tehran University of Medical Sciences, Islamic Azad University, Tehran, Iran ${ }^{2}$ Multidisciplinary Department of Medical-Surgical and Dental Specialties, Dental School, University of Campania Luigi Vanvitelli, Naples, Italy ${ }^{3}$ Department of Periodontics and Oral Medicine, School of Dentistry, University of Michigan, Ann Arbor, MI 48109, USA

aDDS, MSc, Professor; ${ }^{b}$ Undergraduate Dental Student; 'DDS, Executive Manager; ${ }^{\mathrm{a} P}$ ost Doctorate Student; ${ }^{\mathrm{f}}$ Post Doctorate Student; ${ }^{9} \mathrm{DDS}$, Clinical Assistant Professor, Director of Predoctoral Periodontics

ABSTRACT DOI: https://doi.org/10.25241/stomaeduj.2020.7(1).art.7

Background: Relapse is one of the major concerns in the correction of skeletal class III malocclusion

Objective: The purpose of this systemic review was to evaluate the degree of relapse on skeletal class III patients who received bimaxillary surgery or mandibular setback with orthodontic treatment.

Data Sources: A search of the literature was performed in the databases of PubMed, Google Scholar Beta, Scopus, Web of Science, and the Cochrane Library.

Study Selection: Out of the 165 articles identified, 73 studies were obtained, once duplicated articles were excluded. Then, 40 other records were excluded due to titles and abstracts, and 20 were removed for not fulfilling exclusion/ inclusion criteria. 11 studies met the final inclusion criteria. Some cephalometric data during T1-T2-T3 were measured.

Data Extraction: SNA did not have any significant changes within less than 2 years but it increased significantly after 2 years. SNB did not have any significant changes in more than 2 years' follow-up, while it rose significantly in less than 2 years. Overjet decreased significantly after 2 years but not earlier than this duration. Overbite intensified significantly in more than 2 years and not earlier.

OOPEN ACCESS This is an Open Access article
under the CC BY-NC 4.0 license.
Peer-Reviewed Article
Citation: Jamilian A, Nucci L, Fateh A, Toliat M,
Darnahal A, Alassadi M, Wang CW. Stability of skeletal Class
III malocclusion after orthognathic surgery and orthodontic
treatment: a systematic review and meta-analysis.
Stoma Edu J. 2020;7(1):52-67.
Received: February 06, 2020
Revised: February 13, 2020
Accepted: February 14, 2020
Published: February17, 2020
Corresponding author:
Professor Abdolreza Jamilian
Department of Orthodontics, TUMS School of Dentistry,
Cranio-Maxillofacial Research Center, Tehran University of
Medical Sciences, Illamic Azad University, Tehran, Iran
No 14, Pesiyan Ave., Vali Asr St., Tehran, 1986944768, rran
Tel/Fax: 00982122011892, e-mail: info@jamilian.net
Copyright: $\odot$ 2020 the Editorial Council
for the Stomatology Edu Journal.
Data Synthesis: SNA and overbite increased significantly after 2 years. SNB increased significantly before 2 years and did not have any changes after it. Overjet was significantly reduced after 2 years.

\section{KEYWORDS}

Class III; Skeletal and Dental Changes; Stability; Bimaxillary Surgery or Mandibular Setback; Systematic Review and Meta-Analysis.

\section{INTRODUCTION}

Moderate to severe skeletal class III patients often require a combined orthodontic and surgical approach for treatment. It has been reported that skeletal class III malocclusion is the most frequent deformity corrected by combined orthognathic surgery and orthodontic treatment [1-4]. However, bimaxillary surgery has gradually become more popular to correct class III malocclusion [5-7].

It has been estimated that $20 \%$ to $25 \%$ of all Class III cases have true mandibular prognathism suggesting that at least $75 \%$ of all class III malocclusions have some degree of maxillary retrusion. Given this scenario, the surgical treatment has been regarded as the best approach to achieve the best results in adult cases [8]. Post-surgical relapse is one of the major concerns in the correction of skeletal class III malocclusion. It has been shown that there is a greater tendency for relapse after bimaxillary osteotomy [9]. Similarly, LaBanc et al [10] reported that due to increased incidence of relapse, bimaxillary surgery should only be performed for specific indications; for example two-jaw surgery has greater relapse than single-jaw surgery.

On the contrary, Proffit et al [11] found that better stability and predictable results can be obtained after two-jaw surgery. Immediate relapse can be identified after surgery which may occur due to intraoperative error such as imprecise planning, inaccurate osteosynthesis, or failure to fix the joint. On the other hand, late relapse can be detected 


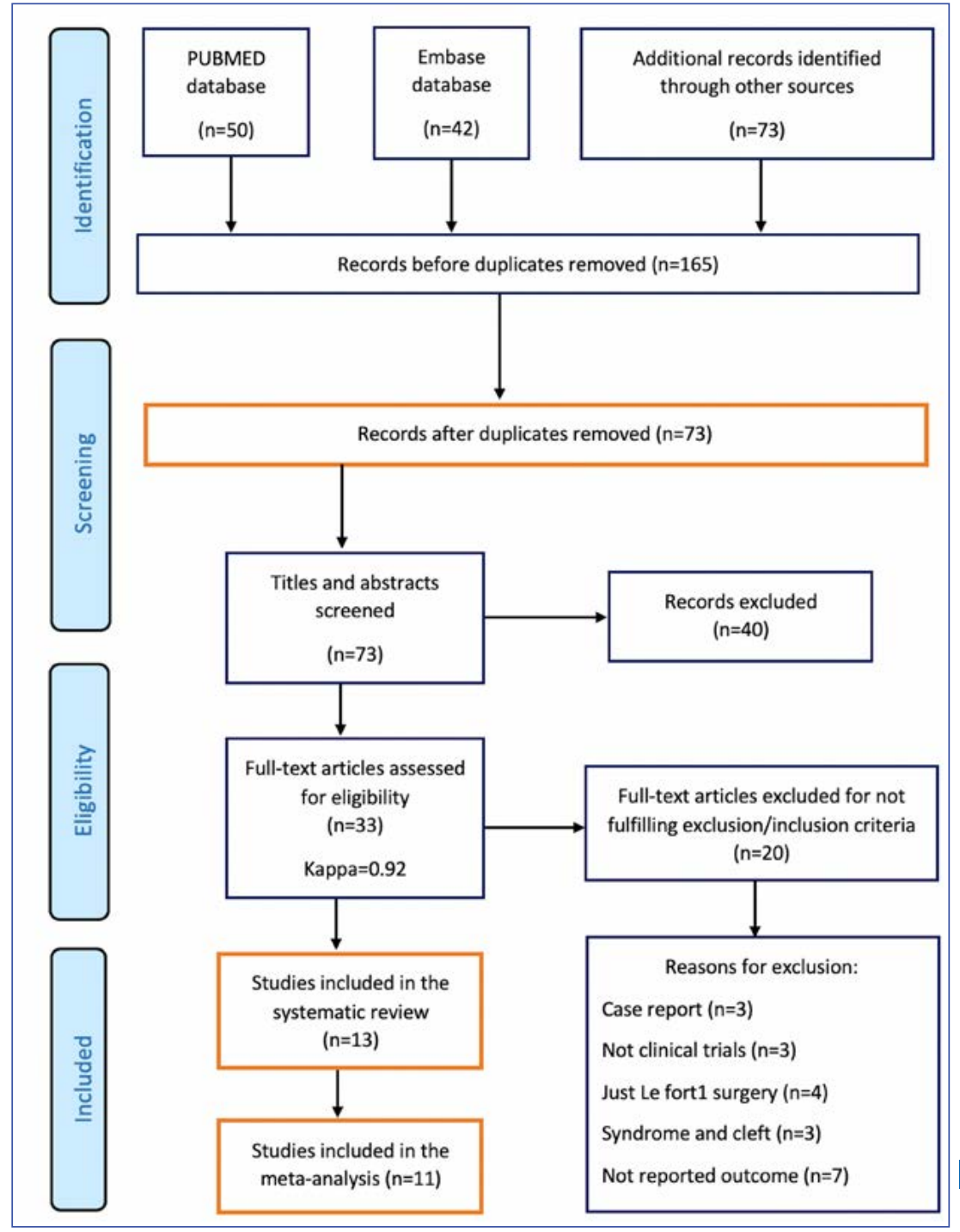

Figure 1. PRISMA flowchart of article retrieval.

once a considerable period has elapsed since the day of the surgical procedure. Late relapse may occur due to unstable occlusal relationships, growth spurts, absence of myofunctional adaptation, or persistent tongue or orofacial muscle habits [12]. A study [5] revealed that the rate of short-term relapse of bilateral sagittal split osteotomy setback surgery is $9.9 \%-62.1 \%$, and long-term relapse is between $14.9 \%$ and $28.0 \%$, at point $B$.

To the best of our knowledge, there has been no meta-analysis evaluating the stability of skeletal changes after a combined orthodontic and surgical procedure for treatment of skeletal Class III patients in short- and long-term follow ups.

The question is: "How much of the treatment effects remains stable by the end of follow-up?"

Objectives: The aim of this study was a meta-analysis of the literature on the stability of skeletal class III malocclusion.

Patients often require a combined orthodontic and surgical approach after bimaxillary surgery. This meta-analysis was undertaken to explore the parameters related to the skeletal stability in surgical correction of skeletal Class III malocclusion.

\section{MATERIALS AND METHODS}

\subsection{Protocol and registration}

This systematic review was based on a specific protocol developed and piloted following the guidelines outlined in the PRISMA-P statement [13]. Furthermore, the procedure and reporting followed the guidelines of the Cochrane Handbook for Systematic Reviews of Interventions [14] and the PRISMA statement, [15] respectively.

2.2. Information sources, search strategy, and study selection

A literature search was performed using PubMed, Google Scholar Beta, Scopus, Web of Science, and the Cochrane Library to identify articles reporting combined orthodontic and surgical approach for treatment of skeletal class III malocclusion in nongrowing patients.

The search process was conducted independently by two coauthors (AJ and AD) for articles published up to December 2018.

All titles and abstracts were evaluated, and duplicate studies were removed. 


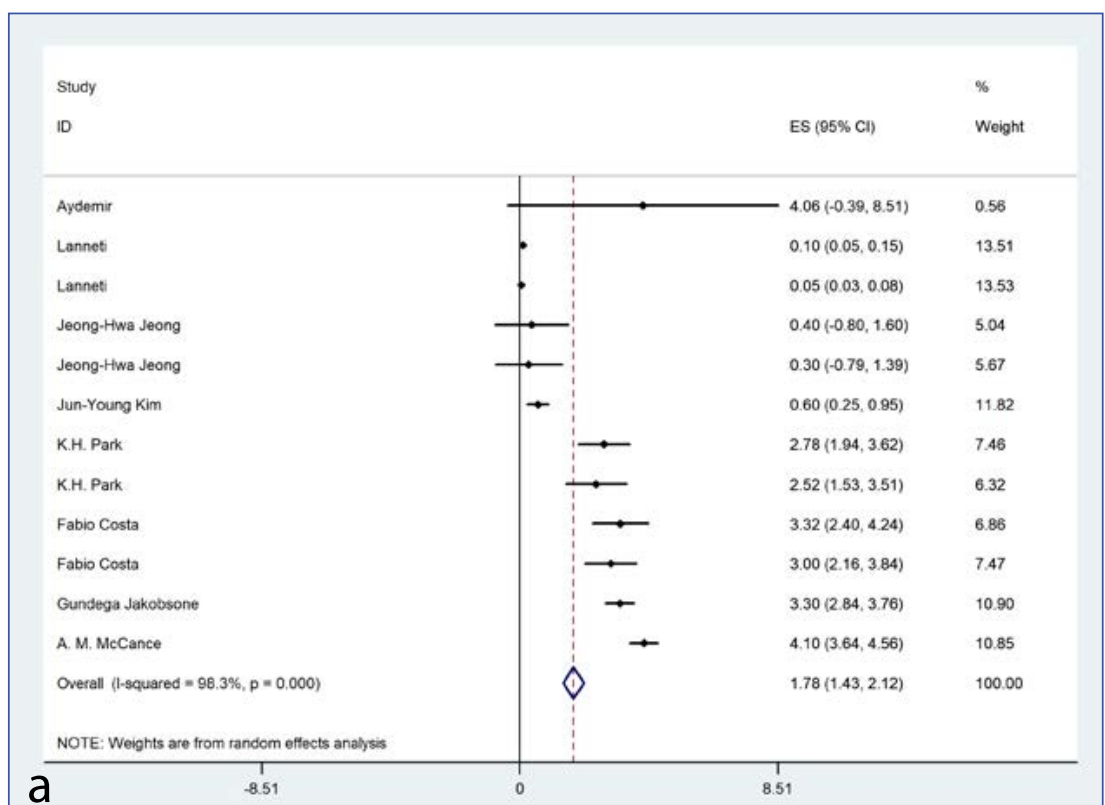

IFigure 2a. Before surgery T1 - After surgery T2, (T1-T2) SNA.

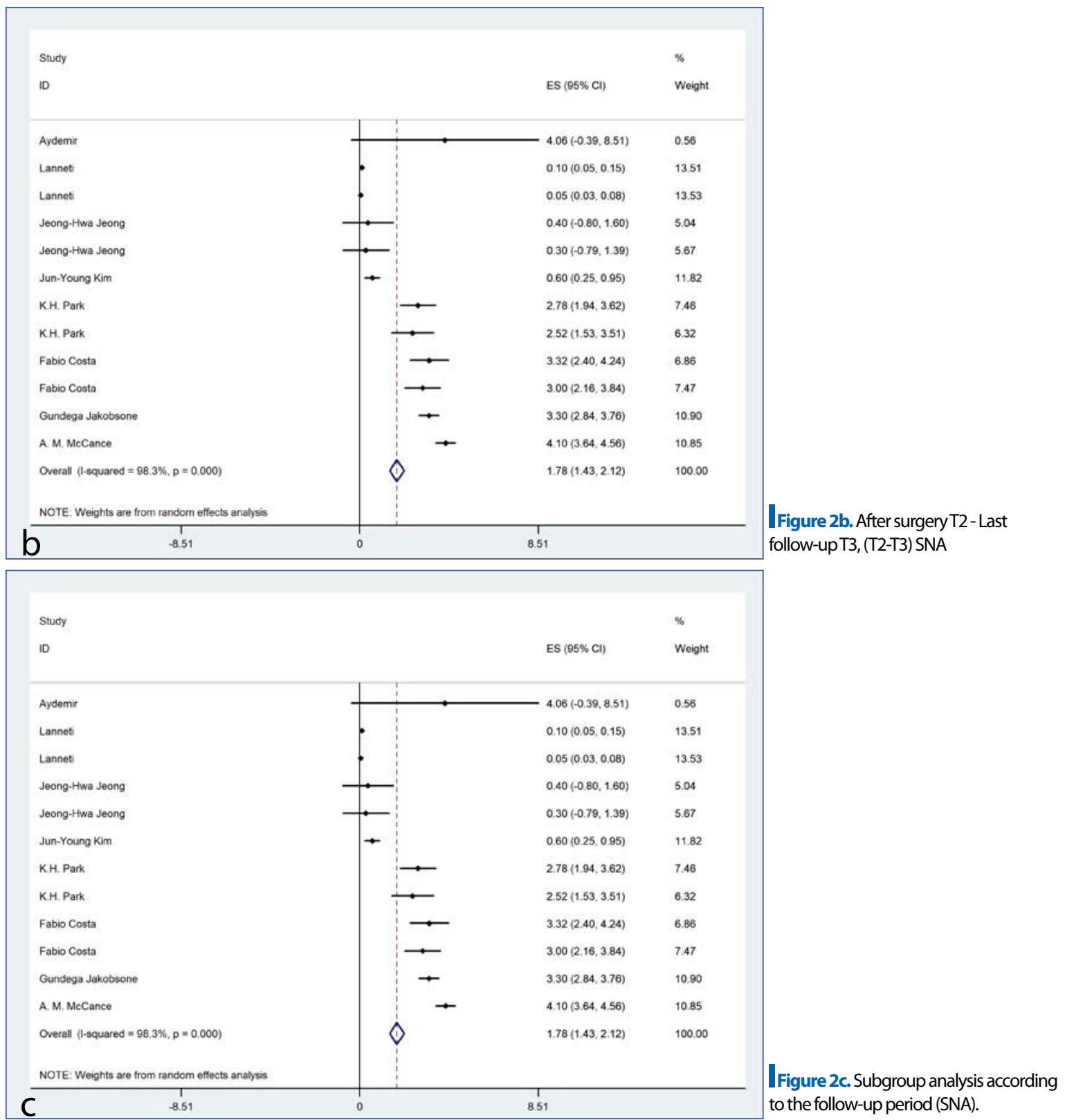

1. Less than 2 years. ; 2 . More than 2 years. 


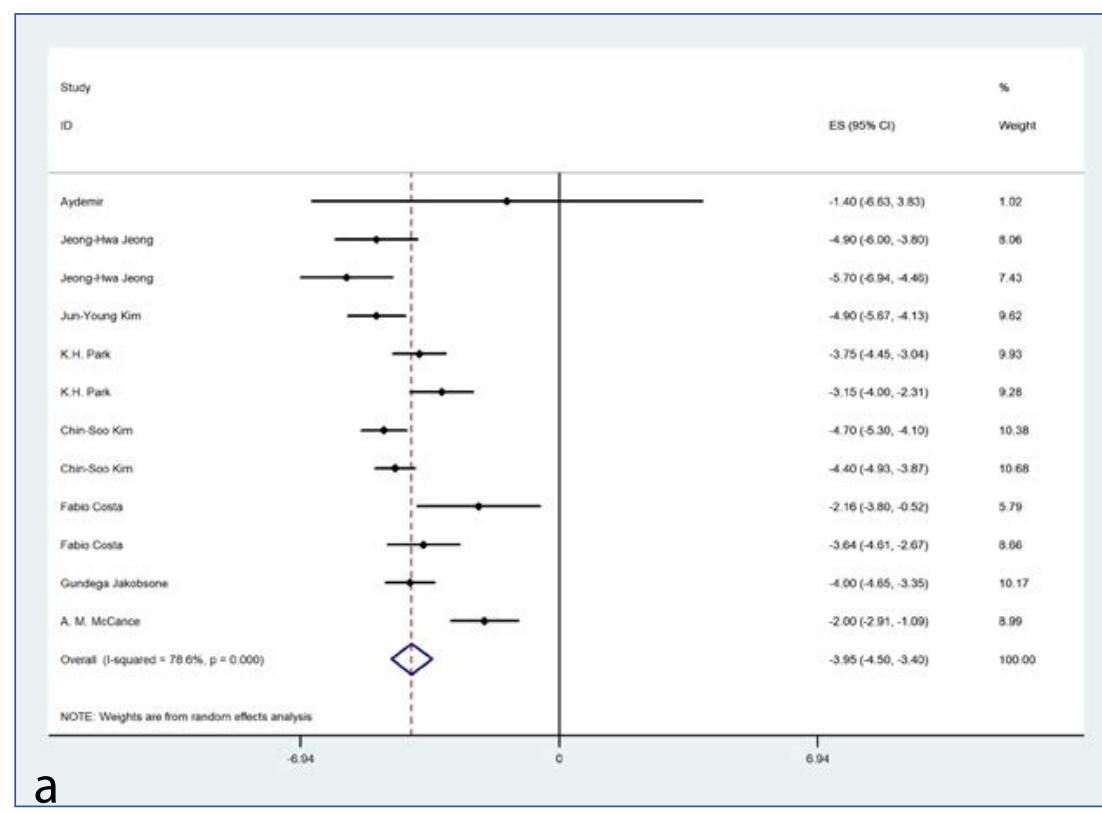

I Figure 3a. Before surgery T1 - After surgery T2, (T1-T2) SNB.

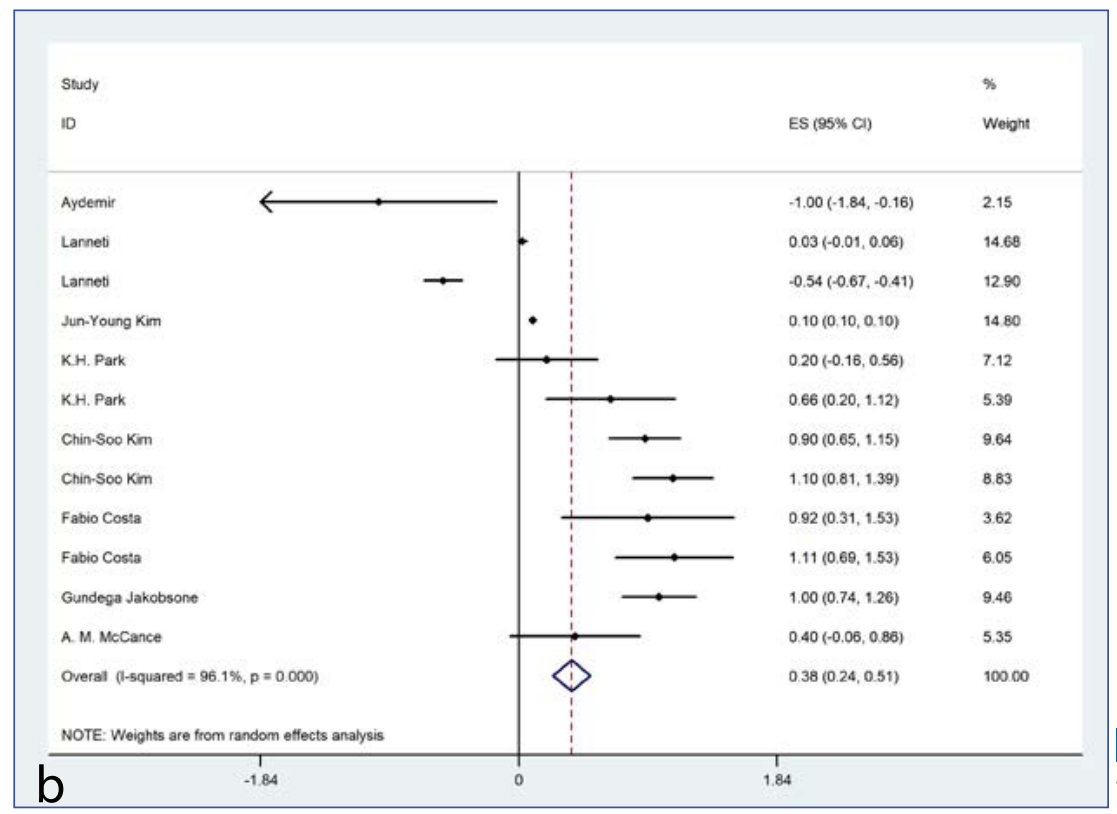

I Figure 3b. After surgery T2 - Last follow-up T3, (T2-T3) SNB.

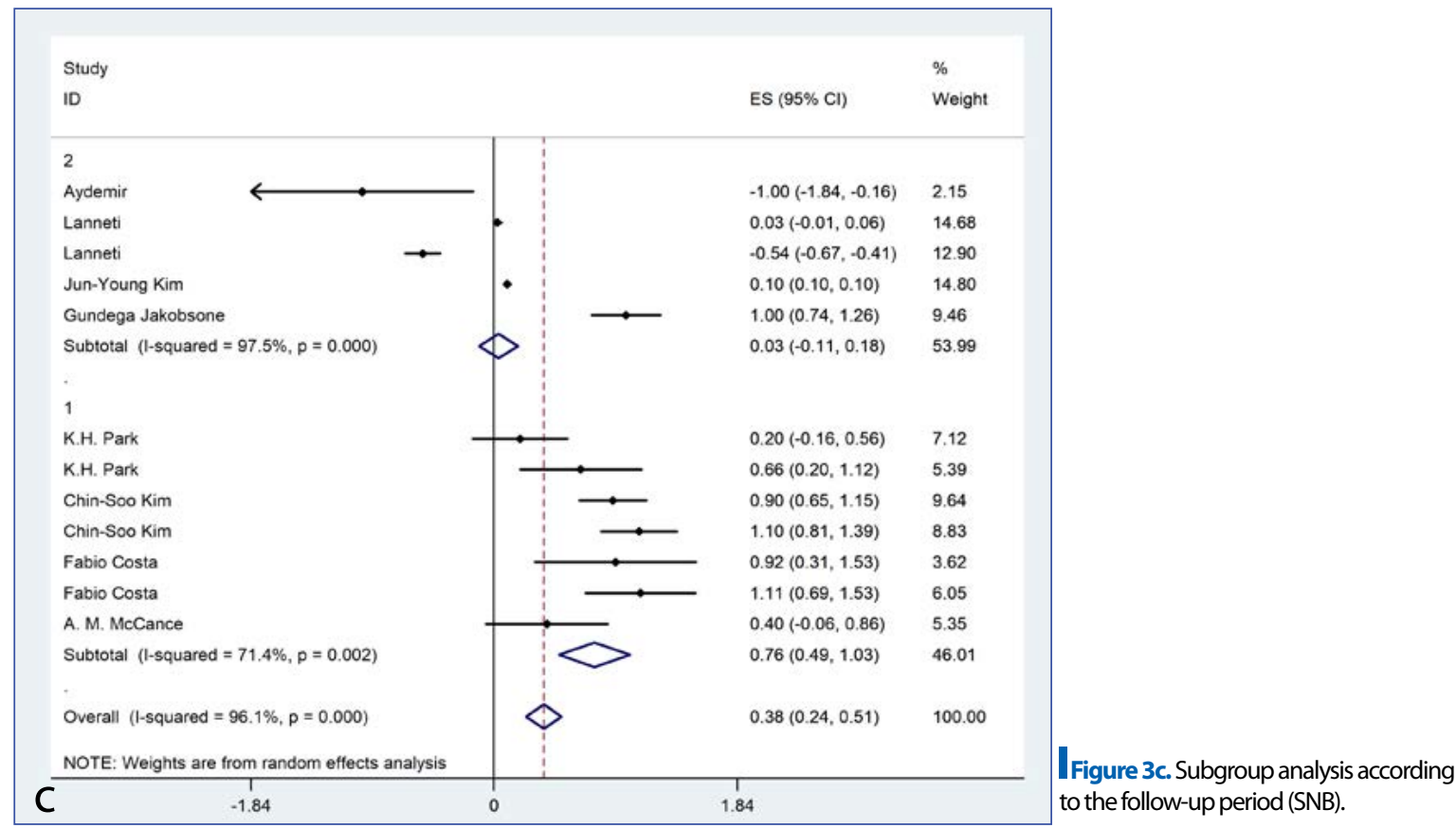

1. Less than 2 years. ; 2 . More than 2 years. 


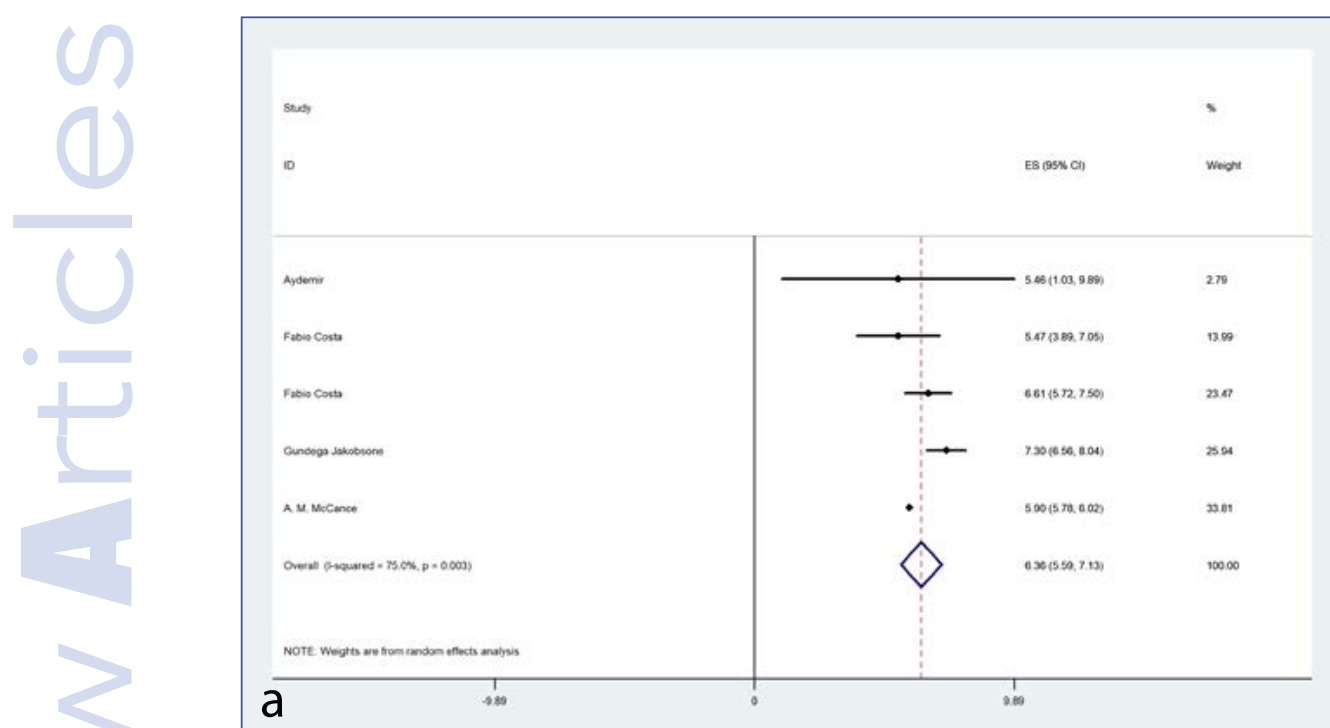

I Figure 4a. Before surgery T1 - After surgery $\mathrm{T}_{2}$, (T1-T2) ANB.

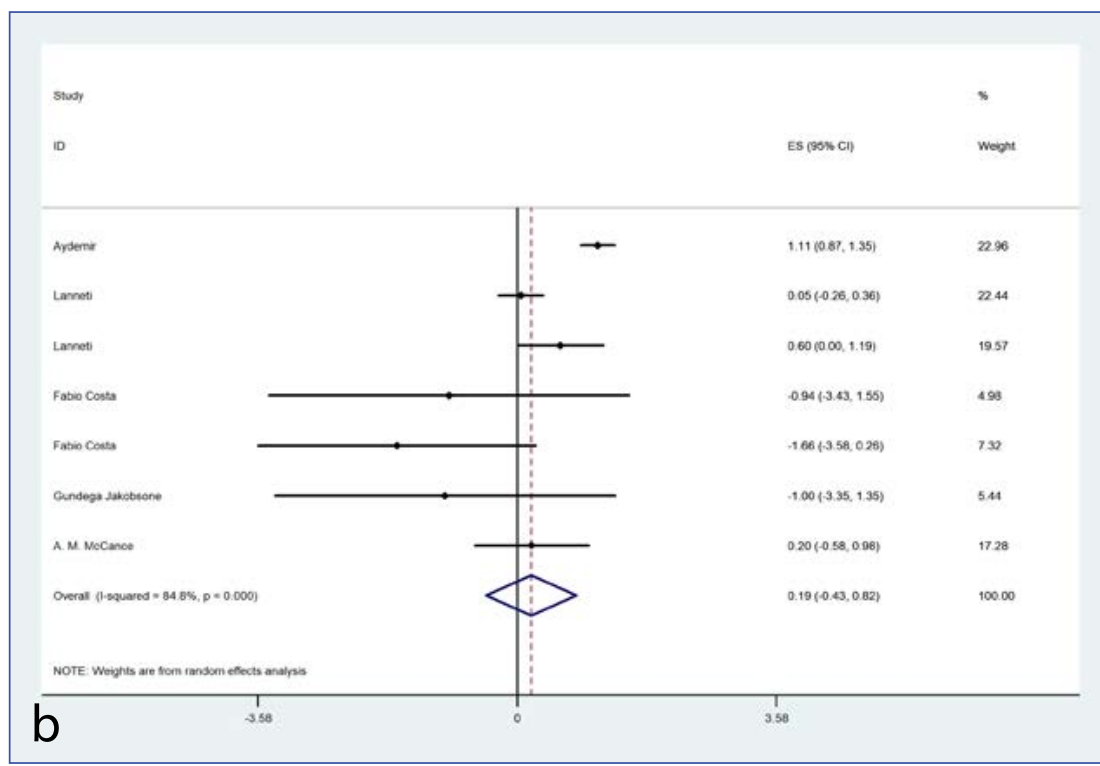

I Figure 4b. After surgery T2 - Last follow-up T3, (T2-T3) ANB.

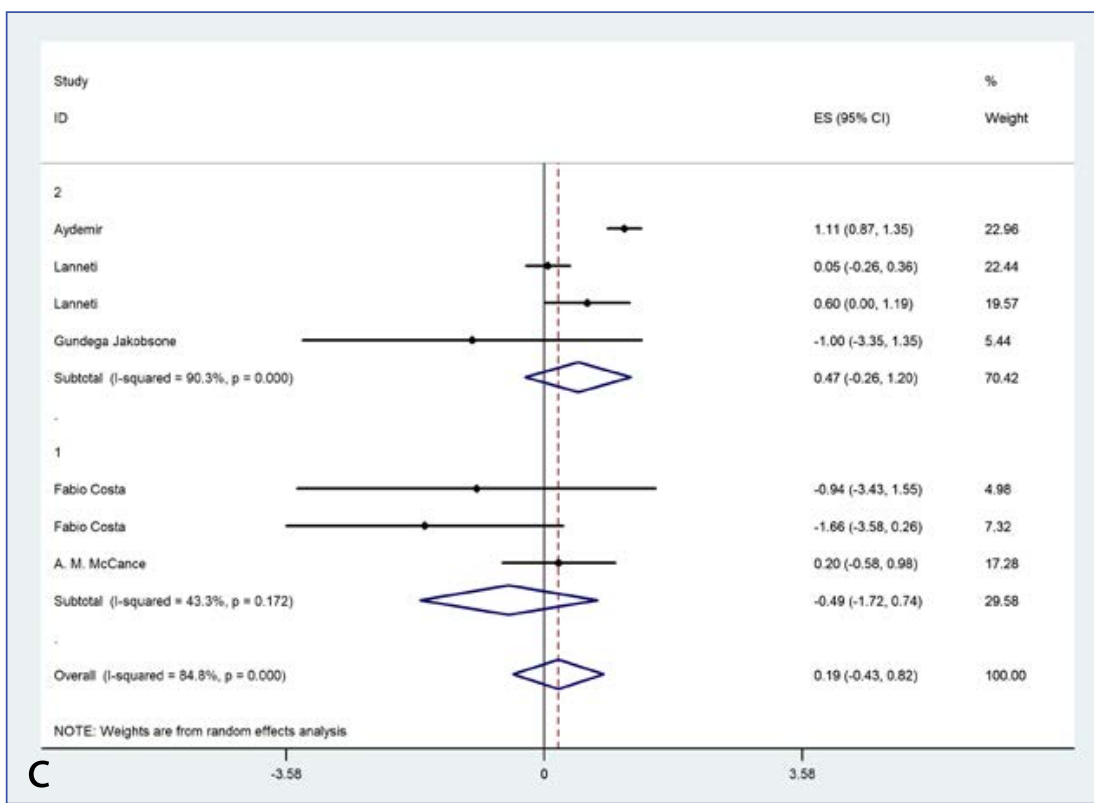

IFigure 4c. Subgroup analysis according 1. Less than 2 years. ; 2 . More than 2 years. to the follow-up period (ANB). 


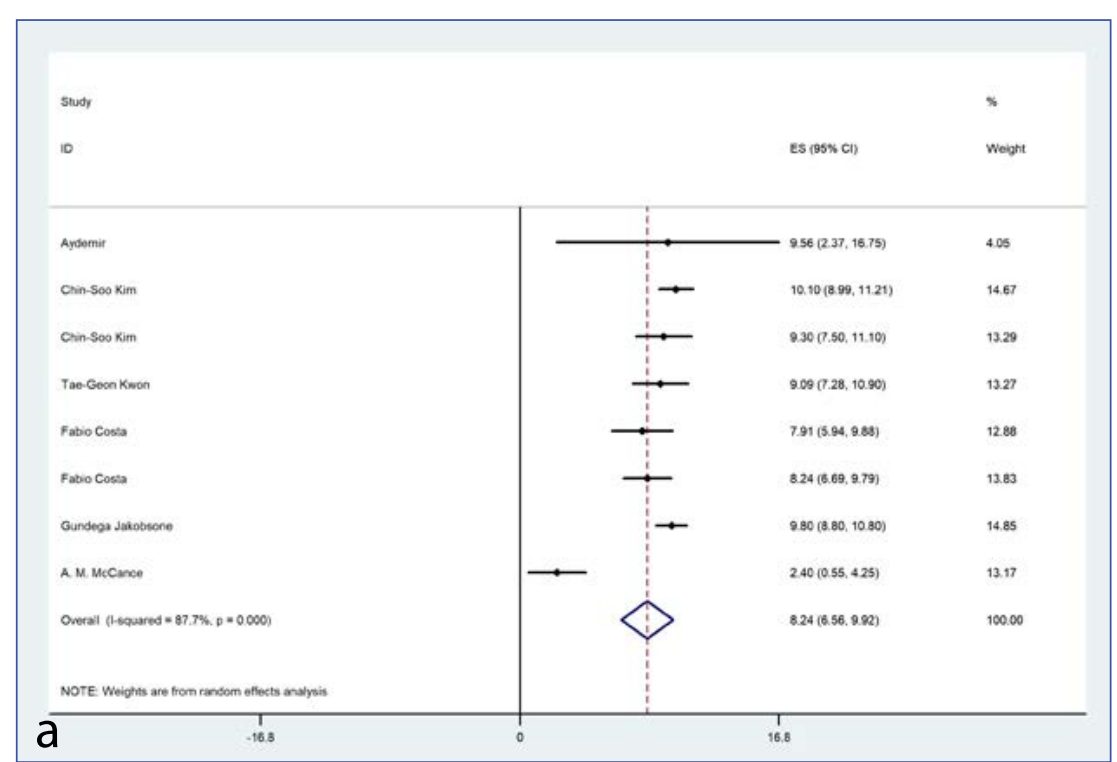

IFigure 5a. Before surgery $\mathrm{T1}$ - After surgery T2, (T1-T2) Overjet.

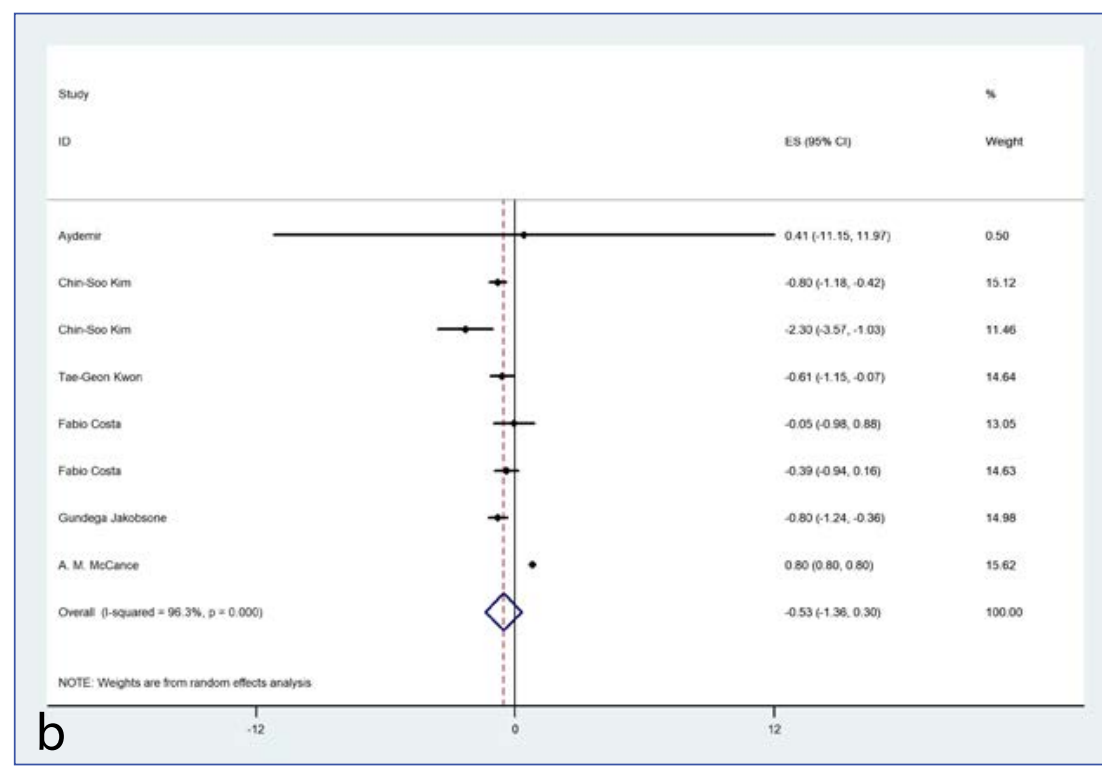

IFigure 5b. After surgery T2-Last follow-up T3, (T2-T3) Overjet.

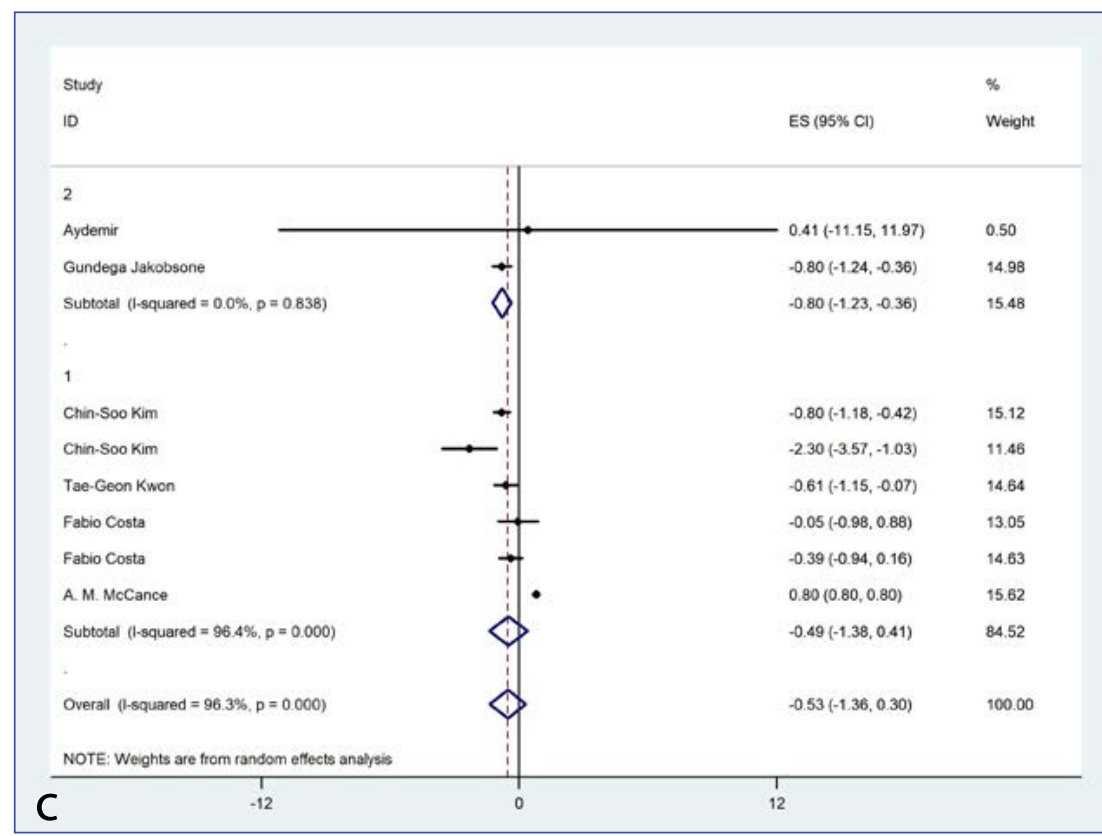

I Figure 5c. Subgroup analysis according to the follow-up period (Overjet).

1. Less than 2 years. ; 2 . More than 2 years. 
Table 1. Eligibility criteria used for the study selection.

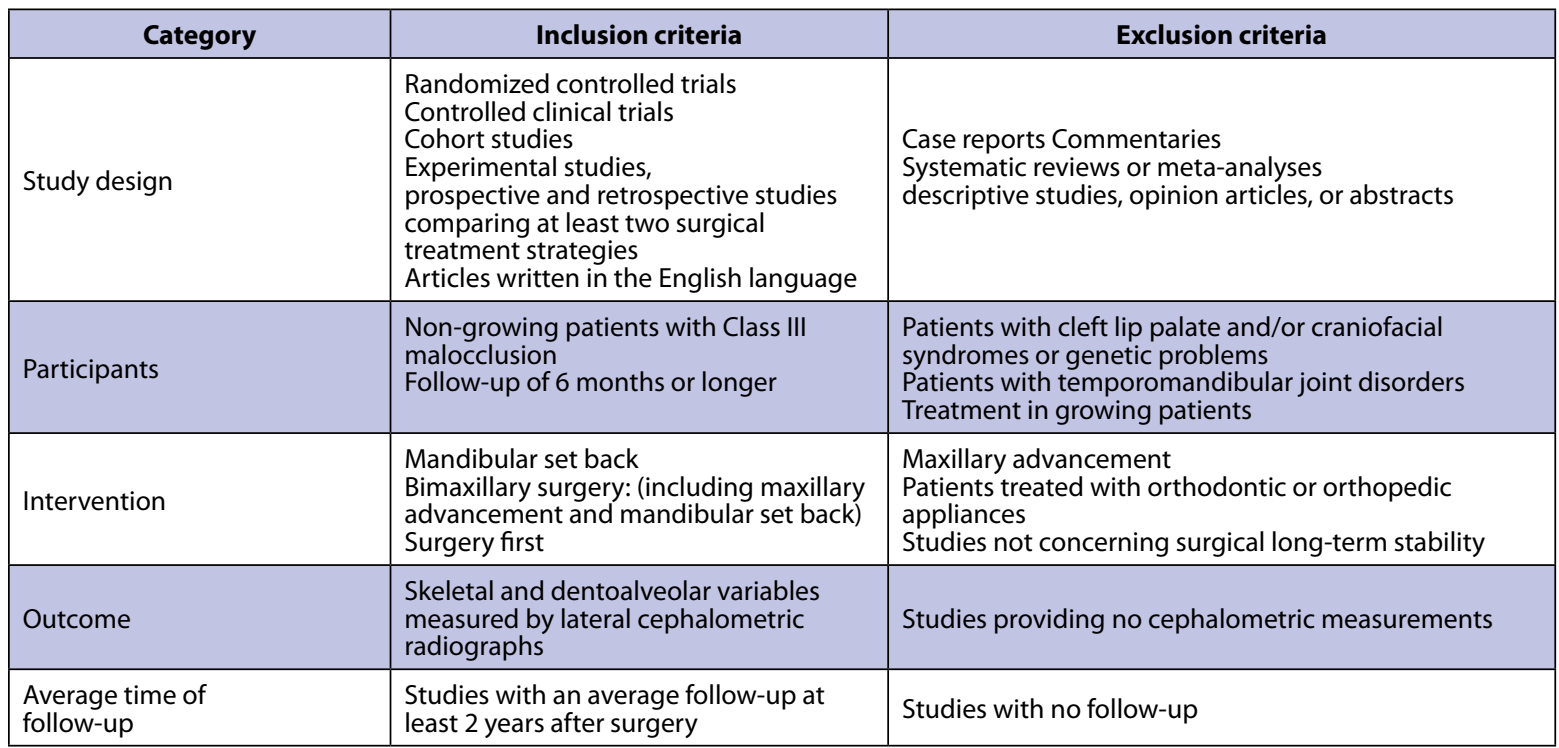

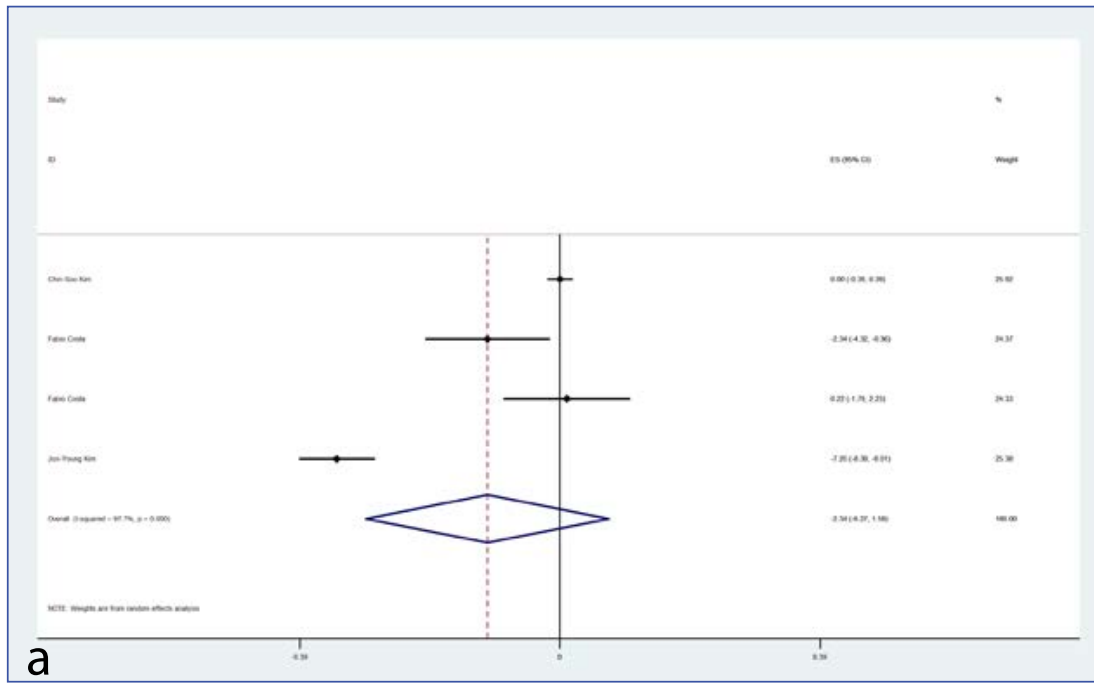

IFigure 7a. Before surgeryT1 - After

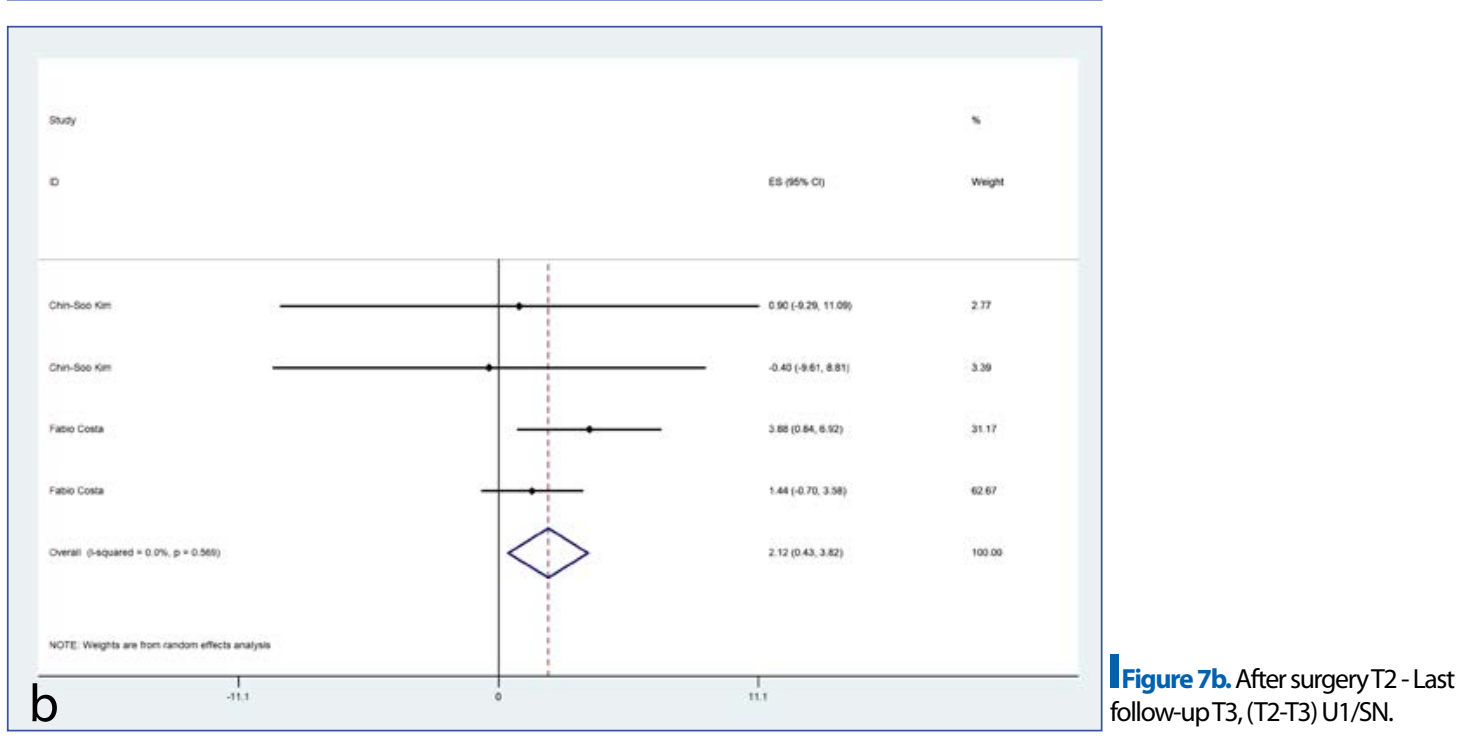
surgery 2 , (T1-T2) U1/SN. 


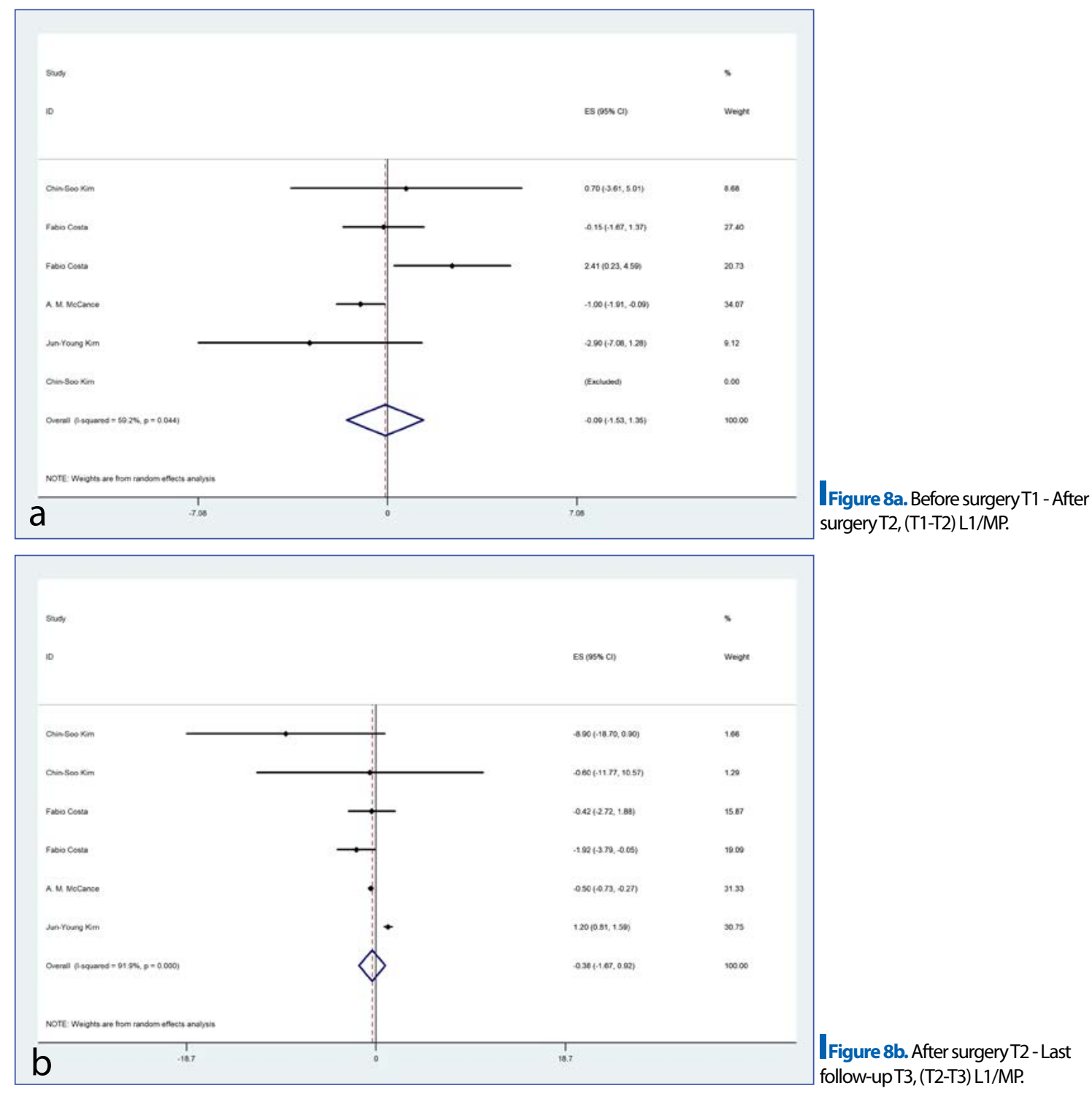

\subsection{Eligibility criteria}

The inclusion and exclusion criteria were established prior to the search according to Table 1.

Each keyword was carefully selected and revised for each database. All keywords used in the search are detailed in Table 2.

This systematic review and meta-analysis was conducted based on the PRISMA (Preferred Reporting Items for Systematic reviews and Meta-Analyses) guidelines [16]. Title-abstract-full text of each article was checked independently by two coauthors based on the PRISMA chart.

\subsection{Data collection and data items}

Two authors (AJ and AD) used pre-defined electronic sheets to extract study characteristics independently. Three time points were defined: T1 (before surgery), T2 (after surgery), and T3 (the end of the follow-up). The findings were obtained on the following items: Name of first author, year of publication, country, number and mean age of patients, gender, type of surgery (Mandibular setback including BSSO or vertical osteotomy) or (Bimaxillary surgery including Lefort $1+$ BSSO or Lefort $1+$ vertical), type of fixation including Rigid Internal Fixation (RIF) or Maxillomandibular Fixation (MMF), follow-up after surgery until 2 years, follow-up after surgery until 5 years, SNA, SNB, ANB, overjet, overbite, incisor mandibular plane angle (IMPA), upper incisor to SN (U1/SN) angle, during T1-T2 (surgical effects), T2-T3 (posttreatment changes) were recorded.

In order to identify the correlation between relapse and cephalometric landmarks, meta-analyses were conducted between cephalometric landmarks and different variables such as type of surgery (mandibular setback including BSSO or vertical osteotomy) or (bimaxillary surgery including Lefort $1+$ BSSO or Lefort $1+$ vertical), type of fixation including Rigid Internal Fixation (RIF) or Maxillomandibular Fixation (MMF), follow-up after surgery within 2 years, followup after surgery within 5 years.

The cut-off value of less than 2 years was chosen to separate short-term from long-term studies. 
Table 2. Keywords used for each data base search.

\begin{tabular}{|c|c|c|c|c|}
\hline Pubmed & Web of science & Scopus & Embase & Cochrane \\
\hline $\begin{array}{l}\text { (((((“Malocclusion, } \\
\text { Angle Class III"[Mesh] OR } \\
\text { "class3"[Title/Abstract]) } \\
\text { OR "class III"[Title/ } \\
\text { Abstract]) OR "Maxillary } \\
\text { Deficiency"[Title } \\
\text { Abstract]) OR "mandibular } \\
\text { protrusion"[Title/ } \\
\text { Abstract]) OR "Maxillary } \\
\text { retrusion "[Title/Abstract]) } \\
\text { AND ((((Mandibular } \\
\text { Osteotomy"[Mesh] OR } \\
\text { "mandibular surgery } \\
\text { "[Title/Abstract]) } \\
\text { OR "bimaxillary } \\
\text { surgery"[Title/ } \\
\text { Abstract]) OR "surgical } \\
\text { orthodontics"[Title/ } \\
\text { Abstract]) OR “mandibular } \\
\text { set back"[Title/Abstract])) } \\
\text { AND (stability[Title/ } \\
\text { Abstract] OR } \\
\text { relapse[Title/Abstract]) }\end{array}$ & $\begin{array}{l}\text { TI=("Malocclusion, } \\
\text { Angle Class III" OR } \\
\text { "class3" OR "class III" OR } \\
\text { "Maxillary Deficiency" OR } \\
\text { "mandibular protrusion" } \\
\text { OR "Maxillary retrusion") } \\
\text { AND TI=("Mandibular } \\
\text { Osteotomy" OR } \\
\text { "mandibular surgery" OR } \\
\text { "bimaxillary surgery" OR } \\
\text { "surgical orthodontics" } \\
\text { OR "mandibular set } \\
\text { back") AND TI=(stability } \\
\text { OR relapse) }\end{array}$ & $\begin{array}{l}\text { ((TITLE-ABS- } \\
\text { KEY("Malocclusion, } \\
\text { Angle Class III") } \\
\text { OR TITLE-ABS-KEY } \\
\text { ("class3") OR TITLE- } \\
\text { ABS-KEY ("class III") } \\
\text { OR TITLE-ABS-KEY } \\
\text { ("Maxillary Deficiency") } \\
\text { OR TITLE-ABS- } \\
\text { KEY ("mandibular } \\
\text { protrusion") OR } \\
\text { TITLE-ABS-KEY } \\
\text { ("Maxillary retrusion”))) } \\
\text { AND ((TITLE-ABS- } \\
\text { KEY ("Mandibular } \\
\text { Osteotomy") OR TITLE- } \\
\text { ABS-KEY ("mandibular } \\
\text { surgery") OR TITLE- } \\
\text { ABS-KEY ("bimaxillary } \\
\text { surgery" OR TITLE- } \\
\text { ABS-KEY ("surgical } \\
\text { orthodontics") OR } \\
\text { TITLE-ABS-KEY } \\
\text { ("mandibular set } \\
\text { back"))) AND ((TITLE- } \\
\text { ABS-KEY (stability) } \\
\text { OR TITLE-ABS-KEY } \\
\text { (relapse))) }\end{array}$ & $\begin{array}{l}\text { 'malocclusion angle } \\
\text { class iii':ab,ti OR } \\
\text { 'class3':ab,ti OR 'class } \\
\text { iii':ab,ti OR'maxillary } \\
\text { deficiency':ab,ti } \\
\text { OR'maxillary } \\
\text { retrusion':ab,ti } \\
\text { and 'mandibular } \\
\text { osteotomy':ab,ti } \\
\text { OR'mandibular } \\
\text { surgery':ab,ti } \\
\text { OR 'bimaxillary } \\
\text { surgery':ab,ti } \\
\text { OR'surgical } \\
\text { orthodontics':ab,ti } \\
\text { OR'mandibular } \\
\text { set back':ab,ti and } \\
\text { 'stability':ab,ti OR } \\
\text { 'relapse':ab,ti }\end{array}$ & $\begin{array}{l}\text { ("Malocclusion, Angle } \\
\text { Class III" OR "class3" OR } \\
\text { "class III" OR "Maxillary } \\
\text { Deficiency" OR } \\
\text { "mandibular protrusion" } \\
\text { OR "Maxillary retrusion") } \\
\text { AND ("Mandibular } \\
\text { Osteotomy" OR } \\
\text { "mandibular surgery" OR } \\
\text { "bimaxillary surgery" OR } \\
\text { "surgical orthodontics" } \\
\text { OR "mandibular set } \\
\text { back") AND (stability OR } \\
\text { relapse) }\end{array}$ \\
\hline
\end{tabular}

\subsection{Statistical analysis}

All statistical tests were conducted using the STATA 14 (StataCorp LP, College Station, USA). The effects of bimaxillary surgery or mandibular setback on SNA, SNB, ANB, overjet, overbite, incisor mandibular plane angle (IMPA) and upper incisor to SN (U1/ SN) angle, before and after surgery as well as the last follow-up were measured by weighted mean difference (WMD) and the 95\% confidence intervals (CI). The standard error (SE) of the mean difference (MD) for non-reported studies was calculated by the following formula: $S D^{2}$ baseline $+S D^{2}$ final $-\left(2 R^{*} S D\right.$ baseline + SD final) and $S D=S E^{*} S q(n)$. Heterogeneity across studies was assessed using the I-squared and the alpha of 0.05 for statistical significance.

The subgroup analysis was based on the time of follow-up to identify the source of heterogeneities. To identify the source of clinical heterogeneity, susceptible variables including treatment plan, gender, country, treatment time, type of surgery, type of fixation, and follow-up time were introduced into a meta-regression model. WMD with $95 \% \mathrm{CI}$ was calculated for all variables. The publication bias was determined using Begg tests. The p-value of 0.05 was regarded for statistical significance. The changes in seven variables (SNA, SNB, ANB, IMPA, overjet, U1/SN, and L1/MP) during three time periods [Before surgery (T1), after surgery (T2) and last follow-up (T3)] were compared between the studies. The summarized data of included studies and cephalometric measurements of the included studies are seen in Tables 3 and 4 respectively. The results of the statistical analysis for heterogeneity and the funnel plots are displayed in Figures 2, 3, 4, $5,6,7$, and 8 .

\section{RESULTS}

\subsection{Study selection and characteristics}

Of the 165 records resulting from the search strategies, 73 studies were obtained once duplicated articles were excluded. Then, 40 papers were removed because of their titles and abstracts. In addition, 20 more were further excluded for not meeting the exclusion/inclusion criteria. Ultimately, 13 papers met the final selected criteria and were selected to conduct the systematic review and meta-analysis. The manual search did not yield any additional material. In case of disagreement, the authors discussed the controversy until an agreement was reached. Of the 13 studies, 2 of them did not provide us with enough data for the meta-analysis and were excluded from the study. Performing meta-analysis was only feasible for 11 studies, and these studies were included in our study. These studies include non-growing patients with Class III malocclusion with Follow-up of 6 months or longer. The level of inter-examiner agreement of data extraction was measured using kappa statistics. The level of agreement between the two examiners was assessed using the Cohen kappa scores. The kappa score for study selection was 0.978 , indicating an excellent level of agreement. The PRISMA flow diagram of study selection is outlined in Fig. 1.

Before surgery T1- After surgery T2, (T1-T2) Figures 2a, 3a, 4a, 5a, 6a, 7a, and 8a.

Short-term treatment effects included significant increase in SNA (WMD 1.78, 95\%Cl:1.42, 2.12), significant reduction in SNB (WMD -3.95, 95\%Cl:$4.50,-3.40$ ), significant rise in ANB (WMD 6.36, 


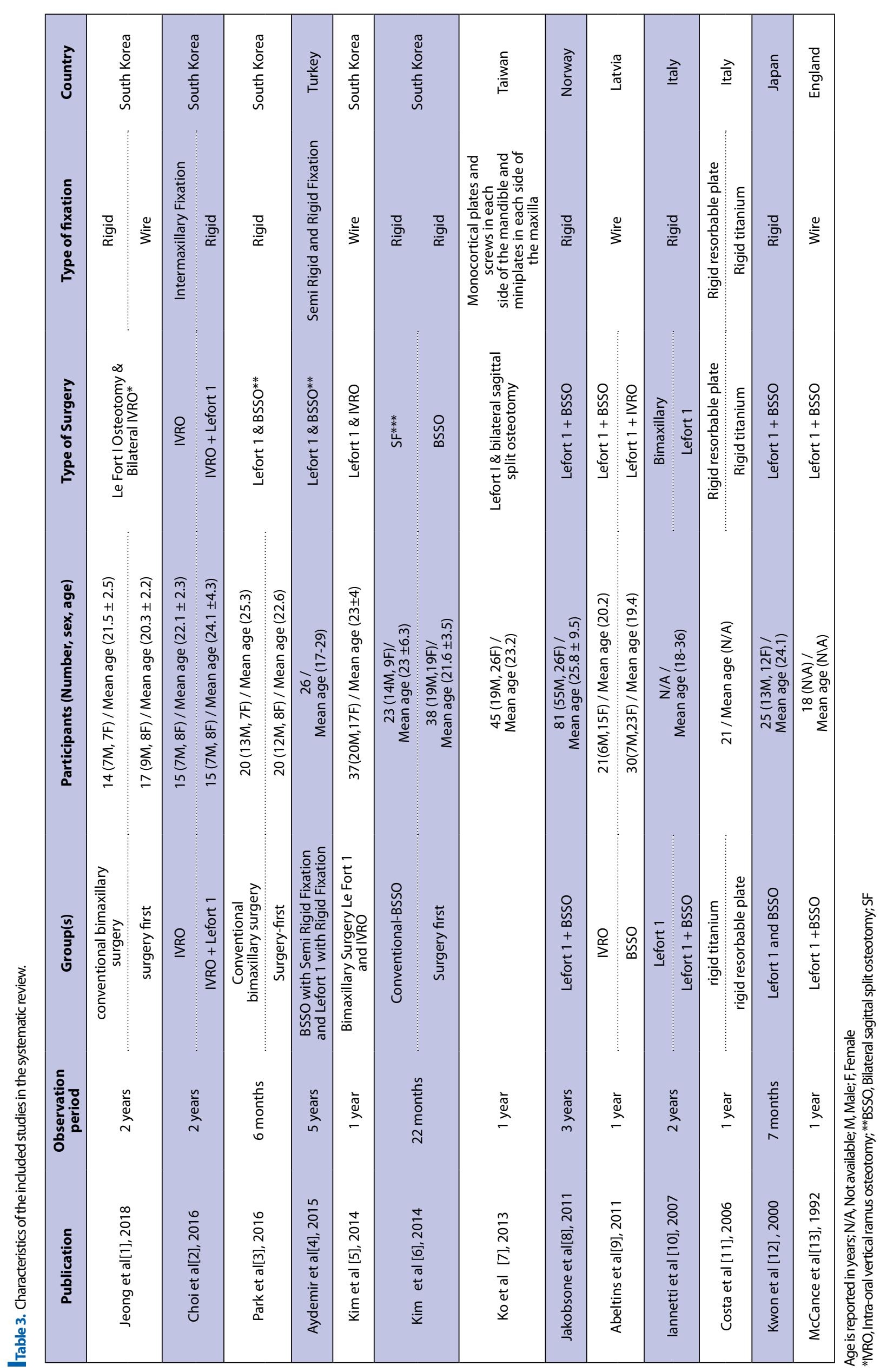


$95 \% \mathrm{Cl}: 5.59,7.13)$, significant growth in overjet (WMD 8.24, 95\%Cl: 6.56, 9.92), significant elevation in overbite (WMD 1.57, 95\%Cl: 0.30,2.84), while U1/ SN (WMD -2.34, 95\%Cl, -6.27, 1.58) and L1/MP (WMD $2.12,95 \% \mathrm{Cl}: 0.43,3.82)$ did not show any significant changes. After surgery T2- Last follow upT3, (T2-T3) Figures $2 b, 3 b, 4 b, 5 b, 6 b, 7 b$, and $8 b$.

The last follow-up showed no significant changes in SNA (WMD 0.06, 95\%Cl:-.05, 0.16), ANB (WMD $0.19,95 \% \mathrm{Cl}:-0.43,0.82)$, overjet (WMD $-0.53,95 \% \mathrm{Cl}$ : $-1.36,0.30$ ), overbite (WMD 0.20, 95\%Cl:-0.17, 0.57), L1/MP (WMD -0.38, 95\%Cl:-1.67, 0.92), while there was a significant change in SNB and U1/SN (WMD 0.38, 95\%Cl:0.24, 0.51) and (WMD 2.12, 95\%Cl:0.43, 3.82 ) respectively.

\subsection{Subgroup analysis}

A subgroup analysis based on the duration of followup: less than 2 years (group 1) and more than 2 years (group 2) was conducted to identify the source of the high heterogeneity and the influence of the follow-up duration.

SNA increased significantly after a 2 year-follow-up [WMD 0.07, 95\%Cl: 0.03, 0.11)] but no significant changes were noted in less than 2 year-follow-up [WMD -0.02, (95\%Cl: $-0.23,0.19)$ ].

SNB did not have any significant changes in more than 2 year-follow-up [WMD 0.03 (95\%Cl: -0.11 , $0.18)$ ]; however, it increased significantly in group 1 [WMD 0.76 (95\%Cl: 0.49, 1.03)].

There were no significant changes in ANB in both group 2 durations [WMD .047 (95\%Cl:-0.26,1.20)] or group 1 [WMD -0.49 (95\%Cl:-1.72, 0.74)] durations. For overjet, it decreased significantly after a 2 yearfollow-up [WMD $-0.80(95 \% \mathrm{Cl}:-1.23,-0.36)]$, but not in less than a 2 year-follow-up [WMD -0.49 (95\%Cl: $-1.38,0.41)]$. Overbite grew significantly in group 2 [WMD 0.50 (95\%Cl:0.01, 0.98)] and not in group 1 [WMD $0.03(95 \% \mathrm{Cl}:-0.36,0.41)]$. Only a few studies measured U1/SN and L1/MP; hence, the heterogeneity could not be measured due to the small sample size. The results of the statistical testing for heterogeneity and the corresponding funnel plots are given in Figures $2 c, 3 c, 4 c, 5 c$, and $6 c$.

\subsection{Risk of bias within studies /publication bias}

No publication bias was determined by using the Begg's test [in STATA 14 (StataCorp LP, College Station, USA)].

The results of the Begg's test for the analysis of small study effect (publication bias) for the measurements of SNA, SNB, ANB, overjet, overbite, U1/SN, and L1/ $\mathrm{MP}$ are as follows, respectively: $0.78,0.33,0.95,0.08$, $0.45,0.98$, and 0.34 .

\section{DISCUSSION}

\subsection{Summary of evidence}

This meta-analysis showed some significant relapse in skeletal and dental variables during the follow-up period. SNA and overbite increased significantly after a 2 year-follow-up. On the contrary, SNB increased significantly before a 2 year-follow-up. Overjet was significantly reduced after a 2 year-follow-up. To the best of our knowledge, this is the first metaanalysis reviewing the stability of skeletal class III malocclusion after bimaxillary surgery or mandibular setback. Data from this study revealed that the main relapse in SNA occurred after a 2 year-follow-up but not in less than 2 years. This suggested that SNA relapse often happened after a 2 year-follow-up and was largely associated with the growth of maxilla that is a common finding in class III malocclusion.

For SNB, a significant increase was noted before a 2 year-follow-up and not after a 2 year-follow-up. This relapse in the short-term is due to the growth of mandible which reportedly can continue even after 18 years of age [17]. Hence, it is important to consider the patient's age and their related growth pattern before bimaxillary surgery and/or mandibular setback treatment. Overjet was reduced significantly in more than a 2 year-follow-up; this relapse is due to an increase in SNB. However, the extent of overbite increased significantly after 2 years. Pre-surgical orthodontic treatment aims to decompensate incisor inclination toward normal values. Orthodontic decompensation allows a greater surgical correction, and this may be a more important factor in the relapse. We should keep in mind that skeletal relapse is masked frequently by compensatory changes in the axial inclination of the teeth [18-21].

Relapse varies considerably between patients and surgeons without any known reason. It is clear that good surgical training, profound experience in orthognathic surgery, and technical refinements by the surgeon are required to have perfect surgical outcomes with regards to esthetics and stability. The orthodontist should prepare the patient before surgery for a perfect coordination and leveling and alignment of both dental arches in transverse width, correct decompensation of the incisors, control of the surgical splint, and its newly defined occlusion to allow correct placement of the mandible during surgery.

The etiology of relapse is multifactorial, including, but not limited to: the proper seating of the condyles, the extent of mandibular setback and maxillary advancement, the soft tissue and muscles, the mandibular plane angle, the remaining growth and remodeling, the skill of the surgeon, and the pre-operative age of the patient [8].

Proffit et al [22] questioned the stability in orthognathic surgery since the stability of the surgical repositioning of the jaws varies considerably depending on the procedure.

In their view, the order of importance starts with the direction of movement, the type of fixation used, and in the end, the surgical technique that has been adopted. 


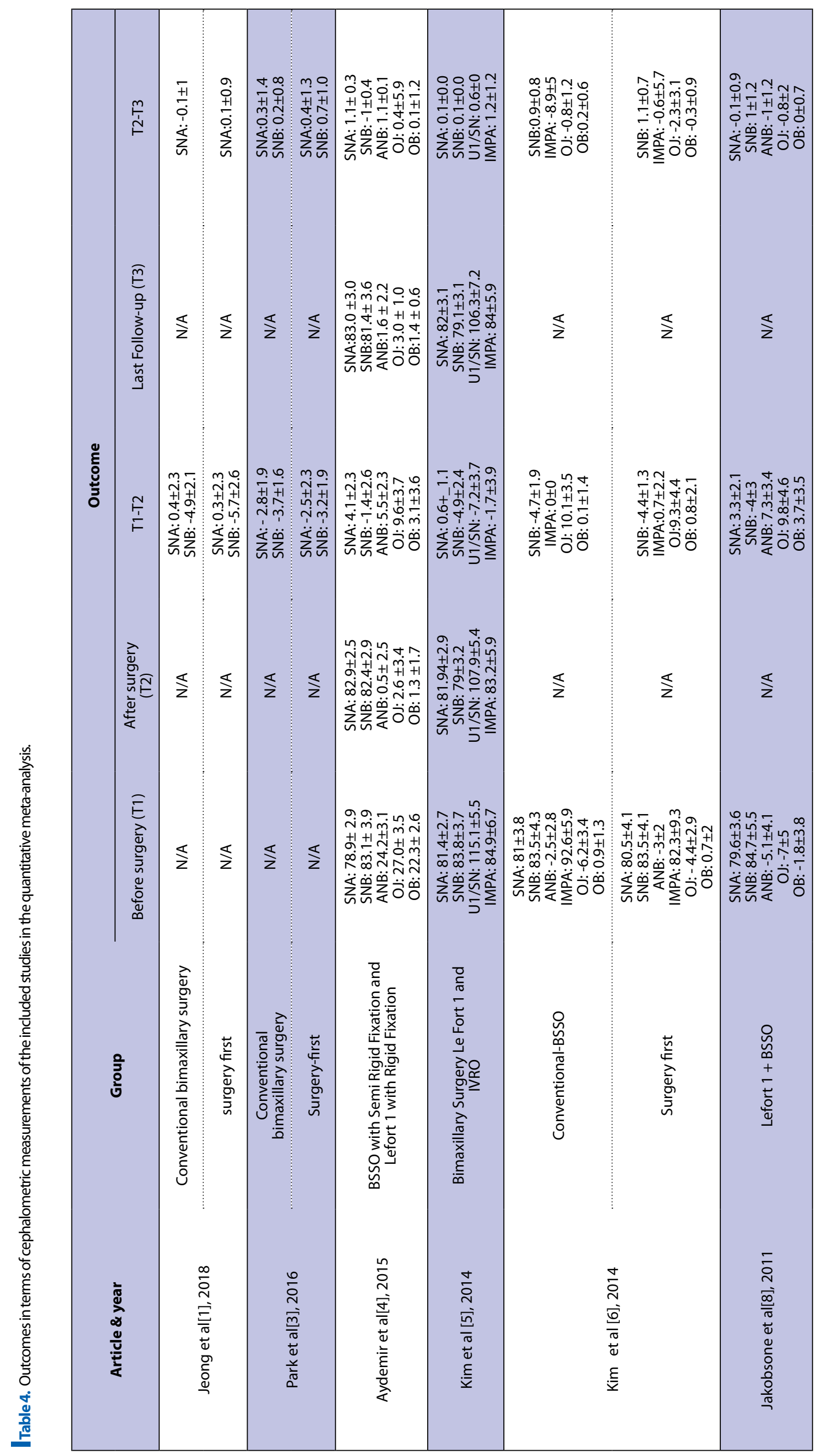




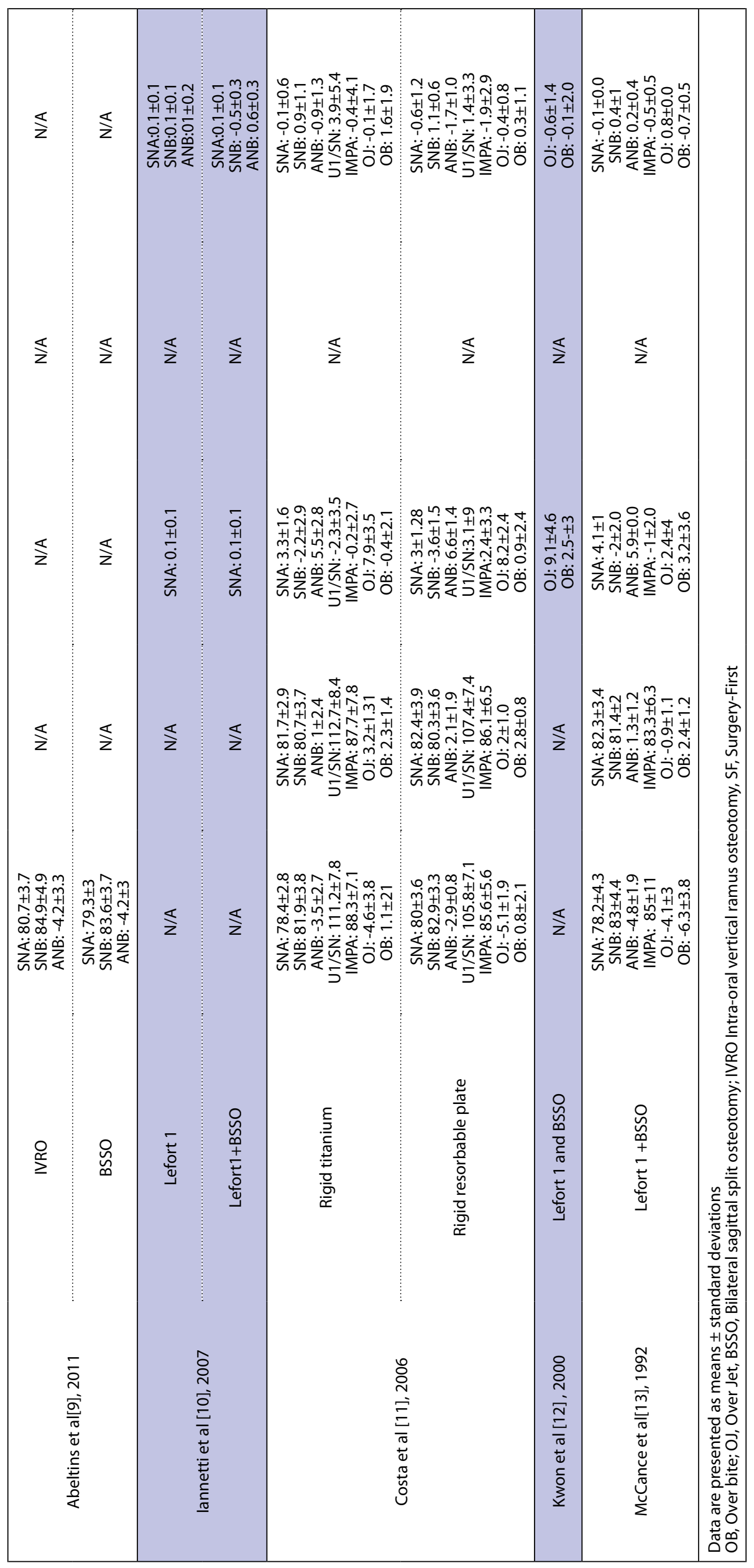




\subsection{Limitations}

This meta-analysis might be considered a first step in addressing the stability of skeletal class III malocclusion after bimaxillary surgery or mandibular setback. Although this study provided an overview of the topic, there were several limitations. One main limitation was the shortage of large and high-quality RCTs. The numbers of relevant research articles and patients included in the meta-analysis were not large enough. Furthermore, the sample sizes were diluted due to too many study variables included ( 7 cephalometric variables at 3 different time points). Hence, the quantitative analysis cannot accurately reflect real skeletal and dental changes. Additionally, not every study included looked at all variables further complicating the analysis. Eventually, some studies proposed surgery first which were deleted from the analysis; however, whether the treatment effects of surgery first can be stable remains unclear. Attention should also be paid to the stability of the treatment effects of surgery first. Therefore, future research in this area is warranted.

\section{CONCLUSIONS}

On the basis of this review, we concluded the following.

1. Surgical orthodontic improves sagittal skeletal and dental relationships but significant relapse during the follow-up period may happen.

2. SNA and overbite increased significantly after a 2 year follow-up.

3. SNB increased significantly before a 2 year followup with no significant changes after this follow-up.

4. Overjet diminished significantly after a 2 year follow-up.

\section{REFERENCES}

1. Chew MT, Sandham A, Wong HB. Evaluation of the linearity of soft to hard-tissue movement after orthognathic surgery. Am J Orthod Dentofacial Orthop. 2008;134(5):665-670.

[Full text links] [CrossRef] [PubMed] Google Scholar Scopus

2. Espeland L, Hogevold HE, Stenvik A. A 3-year patient-centred follow-up of 516 consecutively treated orthognathic surgery patients. Eur J Orthod. 2008;30(1):24-30.

[Full text links] [CrossRef] [PubMed] Google Scholar Scopus

3. Jakobsone G, Stenvik A, Sandvik L, Espeland L. Three-year follow-up of bimaxillary surgery to correct skeletal Class III malocclusion: stability and risk factors for relapse. Am J Orthod Dentofacial Orthop. 2011;139(1):80-89.

[Full text links] [CrossRef] [PubMed] Google Scholar Scopus

4. Jamilian A, Cannavale R, Piancino MG, et al. Methodological quality and outcome of systematic reviews reporting on orthopaedic treatment for class III malocclusion: overview of systematic reviews. J Orthod. 2016;43(2):102-120.

[Full text links] [CrossRef] [PubMed] Google Scholar Scopus

5. Johnston C, Burden D, Kennedy D, et al. Class III surgicalorthodontic treatment: a cephalometric study. Am J Orthod Dentofacial Orthop. 2006;130(3):300-309.

[Full text links] [CrossRef] [PubMed] Google Scholar Scopus

6. Jamilian A, Showkatbakhsh R, Behnaz M, et al. Tooth-borne distraction osteogenesis versus conventional Le Fort I in maxillary advancement of cleft lip and palate patients. Minerva Stomatol. 2018;67(3):117-124.

[Full text links] [PubMed] Google Scholar Scopus

\section{CONFLICT OF INTEREST}

The authors declare no conflict of interest.

\section{FOUNDING}

This manuscript was partially supported by the University of Michigan Graduate Research Fund.

\section{AUTHOR CONTRIBUTIONS}

AJ: conceptualization, study design, study concept, original writing and corresponding author. LN: drafting, data interpretation, drawings and editing. MT and AD: literature review, search design, data gathering. $A F$ and $M A$ : software programs and statistical analysis. CWW: drafting, data interpretation, critical revision and final approval.

\section{ACKNOWLEDGMENTS}

The authors report no commercial, proprietary, or financial interest in the products or companies described in this article.

\section{THE AUTHOR'S INSTITUTIONAL AFFILIATIONS} WHERE THE WORK WAS CONDUCTED

Department of orthodontics, Faculty of dentistry, Cranio maxillofacial Research center, Tehran medical sciences, Islamic Azad University, Tehran, Iran and Department of Periodontics and Oral Medicine, School of Dentistry, University of Michigan, Michigan, USA.

7. Eslami S, Faber J, Fateh A, et al. Treatment decision in adult patients with class III malocclusion: surgery versus orthodontics. Prog Orthod. 2018;19(1):28.

[Full text links] [CrossRef] [PubMed] Google Scholar Scopus 8. Joss CU, Vassalli IM. Stability after bilateral sagittal split osteotomy setback surgery with rigid internal fixation: a systematic review. J Oral Maxillofac Surg. 2008;66(8):1634-1643. [Full text links] [CrossRef] [PubMed] Google Scholar Scopus 9. lannetti G, Chimenti C, Di Paolo C. Five-year follow-up of Le Fort I osteotomies. J Craniomaxillofac Surg. 1987;15(5):238-243.

[Full text links] [CrossRef] [PubMed] Google Scholar Scopus 10. LaBanc JP, Turvey T, Epker BN. Results following simultaneous mobilization of the maxilla and mandible for the correction of dentofacial deformities: analysis of 100 consecutive patients. Oral Surg Oral Med Oral Pathol. 1982;54(6):607-612.

[CrossRef] [PubMed] Google Scholar Scopus

11. Proffit WR, Phillips C, Turvey TA. Stability after surgicalorthodontic corrective of skeletal Class III malocclusion. 3. Combined maxillary and mandibular procedures. Int J Adult Orthodon Orthognath Surg. 1991;6(4):211-225.

[PubMed] Google Scholar Scopus

12. de Haan IF, Ciesielski R, Nitsche T, Koos B. Evaluation of relapse after orthodontic therapy combined with orthognathic surgery in the treatment of skeletal class III. J Orofac Orthop. 2013;74(5):362-369.

[Full text links] [CrossRef] [PubMed] Google Scholar Scopus

13. Shamseer L, Moher D, Clarke $M$, et al. Preferred reporting items for systematic review and meta-analysis 
protocols (PRISMA-P) 2015: elaboration and explanation. BMJ. 2015;350:g7647.

[Full text links] [CrossRef] [PubMed] Google Scholar

14. Higgins JP, Altman DG, Gøtzsche PC, et al. The Cochrane Collaboration's tool for assessing risk of bias in randomised trials. BMJ. 2011;343:d5928.

[CrossRef] Google Scholar

15. Liberati A, Altman DG, Tetzlaff J, et al. The PRISMA statement for reporting systematic reviews and metaanalyses of studies that evaluate health care interventions: explanation and elaboration. J Clin Epidemiol. 2009;62(10):e1e34.

[Full text links] [CrossRef] [PubMed] Google Scholar Scopus

16. Moher D, Liberati A, Tetzlaff J, et al. Reprint--preferred reporting items for systematic reviews and meta-analyses: the PRISMA statement. Phys Ther. 2009;89(9):873-880. [CrossRef] [PubMed] Google Scholar Scopus

17. LoveRJ,MurrayJM,Mamandras AH.Facialgrowthinmales 16to 20years of age.Am JOrthodDentofacialOrthop. 1990;97(3):200-206. [CrossRef] Google Scholar

18. Schendel SA, Epker BN. Results after mandibular advancement surgery: an analysis of 87 cases. J Oral Surg. 1980;38(4):265-282

[PubMed] Google Scholar Scopus

19. Vasir NS, Thompson RT, Davies TM. Dental and skeletal changes following sagittal split osteotomy for correction of mandibular prognathism. Eur J Orthod. 199;13(2):134-142.

[Full text links] [CrossRef] [PubMed] Google Scholar Scopus

20. Grassia V, d'Apuzzo F, DiStasio D, et al. Upper and lower arch changes after mixed palatal expansion protocol. Eur J Paediatr Dent. 2014;15(4):375-380.

[PubMed] Google Scholar Scopus

21. Grassia V, D'Apuzzo F, Ferrulli VE, et al. Dento-skeletal effects of mixed palatal expansion evaluated by postero-anterior cephalometric analysis. Eur J Paediatr Dent. 2014;15(1):59-62.

[PubMed] Google Scholar Scopus

22. Proffit WR, Turvey TA, Phillips C. Orthognathic surgery: a hierarchy of stability. Int J Adult Orthodon Orthognath Surg. 1996;11(3):191-204

[CrossRef] [PubMed] Google Scholar Scopus

23. Jeong $\mathrm{JH}$, Choi $\mathrm{SH}$, Kim KD, et al. Long-term stability of preorthodontic orthognathic bimaxillary surgery using intraoral vertical ramus osteotomy versus conventional surgery. J Oral Maxillofac Surg. 2018;76(8):1753-1762.

[Full text links] [CrossRef] [PubMed] Google Scholar Scopus

24. Choi SH, Cha JY, Park HS, Hwang CJ. Intraoral vertical ramus osteotomy results in good long-term mandibular stability in patients with mandibular prognathism and anterior open bite. $J$ Oral Maxillofac Surg. 2016;74(4):804-810.

[Full text links] [CrossRef] [PubMed] Google Scholar Scopus
25. Park KH, Sandor GK, Kim YD. Skeletal stability of surgeryfirst bimaxillary orthognathic surgery for skeletal class III malocclusion, using standardized criteria. Int J Oral Maxillofac Surg. 2016:45(1):35-40.

[Full text links] [CrossRef] [PubMed] Google Scholar Scopus 26. Aydemir H, Efendiyeva R, Karasu H, Toygar-Memikoğlu U. Evaluation of long-term soft tissue changes after bimaxillary orthognathic surgery in Class III patients. Angle Orthod. 2015;85(4):631-637.

[Full text links] [CrossRef] [PubMed] Google Scholar Scopus

27. Kim JY, Jung HD, Kim SY, et al. Postoperative stability for surgery-first approach using intraoral vertical ramus osteotomy: 12 month follow-up. Br J Oral Maxillofac Surg. 2014;52(6):539-544. [Full text links] [CrossRef] [PubMed] Google Scholar Scopus

28. Kim CS, Lee SC, Kyung HM, et al. Stability of mandibular setback surgery with and without presurgical orthodontics. J Oral Maxillofac Surg. 2014;72(4):779-787.

[Full text links] [CrossRef] [PubMed] Google Scholar Scopus

29. Ko EW, Lin SC, Chen YR, Huang CS. Skeletal and dental variables related to the stability of orthognathic surgery in skeletal Class III malocclusion with a surgery-first approach. J Oral Maxillofac Surg. 2013;71(5):e215-e223.

[Full text links] [CrossRef] [PubMed] Google Scholar Scopus 30. Abeltins A, Jakobsone G, Urtane I, Bigestans A. The stability of bilateral sagittal ramus osteotomy and vertical ramus osteotomy after bimaxillary correction of class III malocclusion. $J$ Craniomaxillofac Surg. 2011;39(8):583-587.

[Full text links] [CrossRef] [PubMed] Google Scholar $\underline{\text { Scopus }}$

31. lannetti G, Fadda MT, Marianetti TM, et al. Long-term skeletal stability after surgical correction in class III open-bite patients: A retrospective study on 40 patients treated with mono- or bimaxillary surgery. J Craniofac Surg. 2007;18(2):350-354.

[CrossRef] Google Scholar Scopus

32. Costa F, Robiony M, Zorzan E, et al. Stability of skeletal Class III malocclusion after combined maxillary and mandibular procedures: titanium versus resorbable plates and screws for maxillary fixation. J Oral Maxillofac Surg. 2006;64(4):642-651.

[Full text links] [CrossRef] [PubMed] Google Scholar Scopus

33. Kwon TG, Mori Y, Minami K, et al. Stability of simultaneous maxillary and mandibular osteotomy for treatment of class III malocclusion: An analysis of three-dimensional cephalograms. J Craniomaxillofac Surg. 2000;28(5):272-277.

[Full text links] [CrossRef] [PubMed] Google Scholar Scopus 34. McCance AM, Moss JP, James DR. Stability of surgical correction of patients with Skeletal III and Skeletal II anterior open bite, with increased maxillary mandibular planes angle. Eur J Orthod. 1992;14(3):198-206.

[Full text links] [CrossRef] [PubMed] Google Scholar Scopus

\section{Abdolreza JAMILIAN DDS, PhD, Professor Department of Orthodontics Faculty of Dentistry \\ Cranio-Maxillofacial Research Center Tehran Medical Sciences Islamic Azad University \\ Tehran, Iran

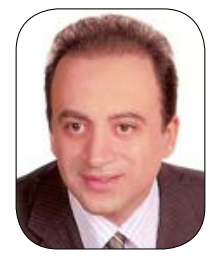

Professor Abdolreza Jamilian is a researcher and specialist in field of Orthodontics. He received his DDS (1991), MSc in Orthodontics (1998), and Fellowship of Orthognathic Surgery \& Craniofacial Syndroms (2010) from the Shahid Beheshti University in Tehran, Iran. He obtained his European Board of Orthodontics in 2013. Now he is a professor at the Islamic Azad University in Tehran. His practice is limited to Orthodontics. He has lectured in several international congresses and has been a consultant for various journals. He has published over 200 original, peer reviewed research and review articles, 15 book chapters and more than 300 scientific communications. He holds 3 patents with the United States Patent and Trademark Office. Research interests: (1) Class 3 malocclusion (2) Cleft lip and palate (3) Orthognathic surgery. 


\section{Ouestions}

\section{Which one is correct regarding stability after surgery.}

$\square$ a. Single jaw surgery has greater relapse than two jaw surgery;

b. Two jaw surgery has greater relapse than single jaw surgery;

$\square c$. There is a controversy regarding the stability of single and two jaw surgery;

$\square$ d. None of them.

\section{What are the causes of late relapse after orthognathic surgery?}

$\square$ a. Unstable occlusal relationships;

ab. Absence of myofunctional adaptation;

Dc. Persistent tongue or orofacial muscle habits;

$\square$ d. All of them.

\section{How much of the Class III malocclusions have true mandibular prognathism?}

口a. $5 \%$ to $10 \%$;

b. $20 \%$ to $25 \%$;

口c. $30 \%$ to $50 \%$;

ad. $50 \%$ to $70 \%$.

\section{How much of the of all class III malocclusions have some degree of maxillary retrusion?}

口a. $15 \%$;

ab. $25 \%$;

ac. $50 \%$;

ad. $75 \%$.

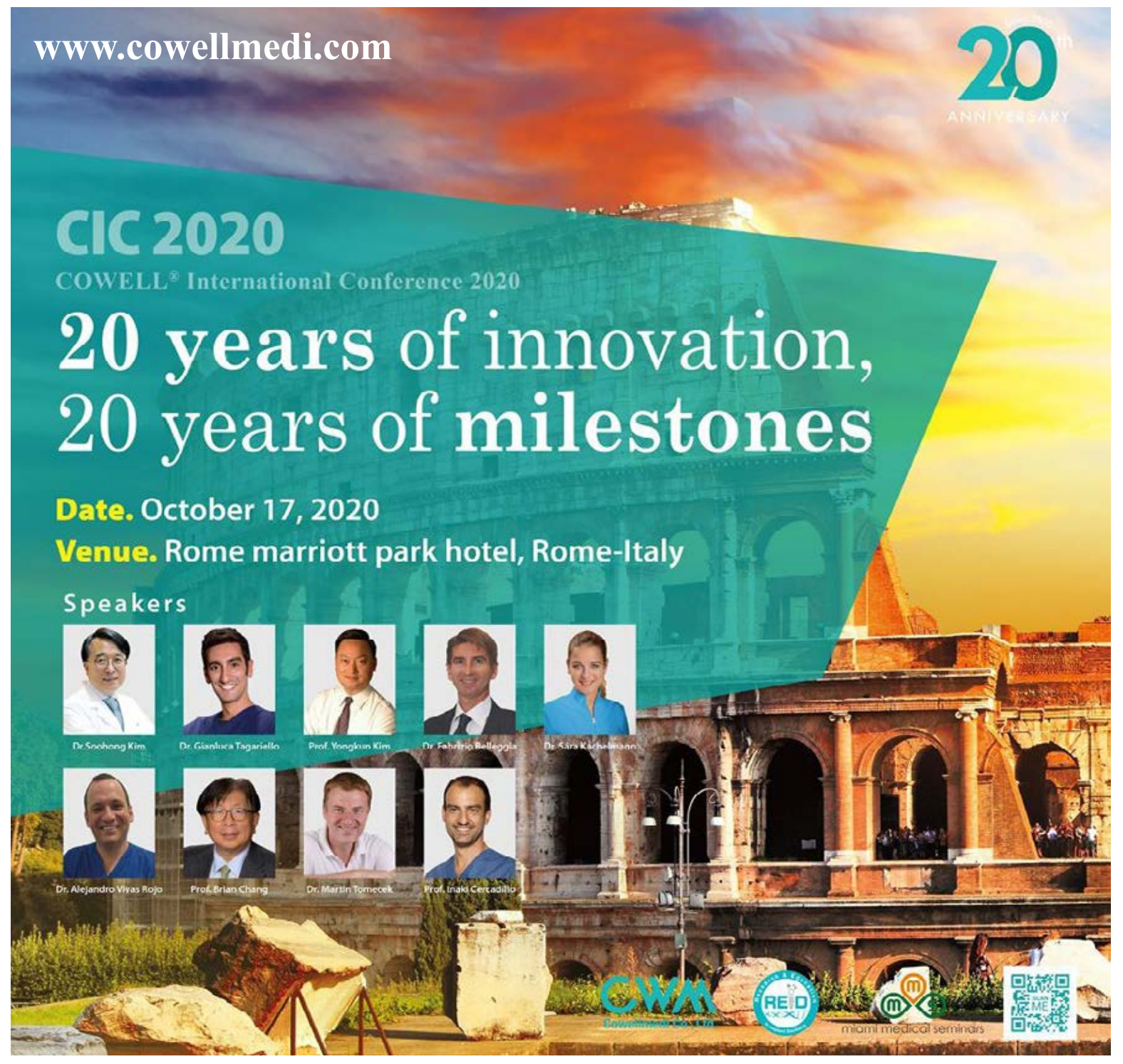

